\title{
Nosocomial Infections and Ventilator-Associated Pneumonia in Cancer Patients
}

\author{
J. V. Divatia, Jacob George Pulinilkunnathil, and \\ Sheila Nainan Myatra
}

\section{Contents}

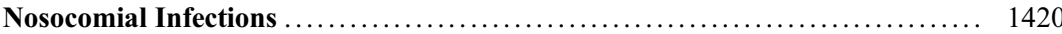

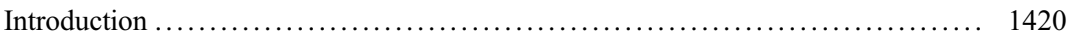

Incidence, Etiology, and Impact of Nosocomial Infections ................... 1420

Risk Factors ................................................. 1421

Treatment and Prevention of Nosocomial Infections ..................... 1421

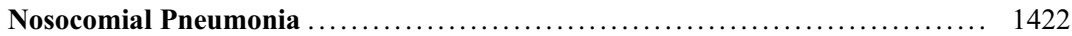

Definition of Ventilator-Associated Pneumonia .......................... 1422

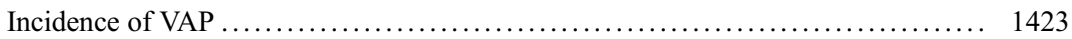

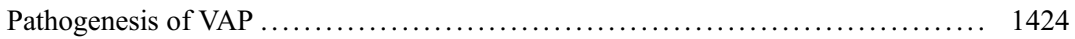

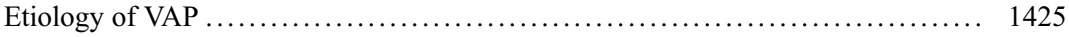

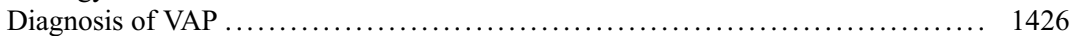

Microbiological Methods for Diagnosis of VAP .......................... 1426

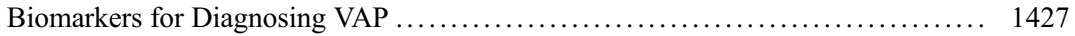

Antimicrobial Treatment .......................................... 1427

Guidelines for Management of Nosocomial Pneumonia ..................... 1428

Prevention of VAP ............................................. 1430

Non-ventilated Hospital-Acquired Pneumonia (NV-HAP) or Hospital-Acquired

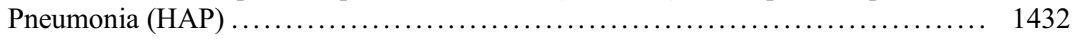

Catheter-Associated Urinary Tract Infections (CAUTI) .................. 1433

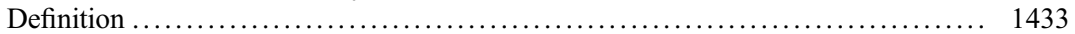

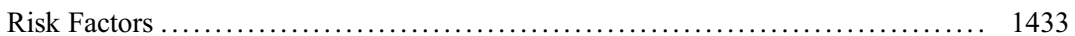

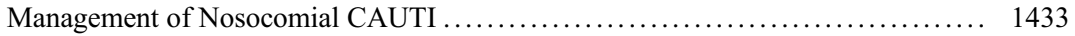

Prevention of CAUTI and CAUTI Bundle ............................ 1434

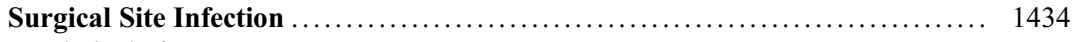

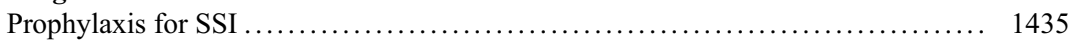

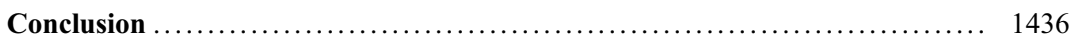

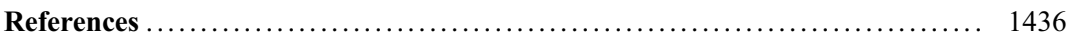

J. V. Divatia $(\bowtie) \cdot J$. G. Pulinilkunnathil $\cdot$ S. N. Myatra Department of Anaesthesia, Critical Care and Pain, Tata Memorial Hospital, Homi Bhabha National Institute, Mumbai, India

e-mail: jdivatia@yahoo.com

\section{Abstract}

Nosocomial infections or healthcare-acquired infections are a common cause of increased morbidity and mortality among hospitalized patients. Cancer patients are at an increased 
risk for these infections due to their immunosuppressed states. Considering these adverse effects on and the socioeconomic burden, efforts should be made to minimize the transmission of these infections and make the hospitals a safer environment. These infection rates can be significantly reduced by the implementing and improving compliance with the "care bundles."

This chapter will address the common nosocomial infections such as ventilatorassociated pneumonia (VAP), catheterassociated urinary tract infections (CAUTI), and surgical site infections (SSI), including preventive strategies and care bundles for the same.

\section{Keywords}

Catheter-associated urinary tract infections

Hospital-acquired infections · Hospitalacquired pneumonia - Nosocomial infections · Surgical site infections - Ventilator-associated pneumonia

\section{Nosocomial Infections}

\section{Introduction}

The term "healthcare-associated infections" (HCAIs) is commonly used to refer to the whole spectrum of infections that a patient acquires from the healthcare environment including hospitals, intensive care units, hospice, nursing homes, etc. Nosocomial infections or hospital-acquired infections (HAIs) are defined by the Centers for Disease Control and Prevention (CDC) as "those infections that were not present in carrier state or incubating state at the time of admission and manifest $48 \mathrm{~h}$ after hospital admission" [24]. These infections are often unrelated to the primary cause of hospital admission and can present even after the hospital discharge of the patients [42]. As per the CDC criteria for surveillance, nosocomial infection sites can be of 9 types affecting over 35 infection sites that can be differentiated on the basis of microbiological and clinical criteria [11]. Patients in intensive care units (ICUs) are more vulnerable to nosocomial infections. The
Extended Prevalence of Infection in Intensive Care (EPIC II) study showed a prevalence of infections within the ICU as high as $51 \%$ [82]. Nosocomial infections are associated with worse outcomes including increased length of hospital stay, long-term disability, and increased mortality rate, and are associated with increased antibiotic use and antibiotic resistance [42]. Due to the multiple risk factors like immunosuppression, disrupted skin and mucosal barriers, recurrent hospital visits, exposure to multiple antibiotics, and the presence of invasive lines and other devices, cancer patients, irrespective of whether they have solid or hematologic malignancies, are at high risk for nosocomial infections [20]. As cancer patients are increasingly being admitted to ICUs for management of diseaseand treatment-related complications, the incidence of nosocomial infections is also increasing in ICUs caring for cancer patients [5]. The common nosocomial infections are catheter-related bloodstream infection (CRBSI), catheter-associated urinary tract infections (CAUTI), surgical site infections (SSI), and ventilator-associated pneumonia (VAP). This chapter will focus on VAP, CAUTI, and SSI, and central line-related bloodstream infection will be dealt with separately.

\section{Incidence, Etiology, and Impact of Nosocomial Infections}

Hospital-acquired infection is common across all parts of the world, with an estimated incidence of $5-10 \%$ in developed countries and up to $30 \%$ in developing countries [72]. Data from the International Nosocomial Infection Control Consortium (INICC) suggests that among developing countries, the CRBSI rates were 4.1 per 1,000 central venous catheters (CVC)-days, ventilator-associated pneumonia (VAP) rates were 12.2 per 1,000 ventilator-days, and the catheter-associated urinary tract infection (CAUTI) rates were 5.07 per 1000 catheter-days [68]. With increased awareness and constant vigilance, there has been a steady and gradual decrease in the incidence rates of hospital-acquired infections with a $50 \%$ reduction in central line-associated bloodstream 
Table 1 NHSN and INICC benchmarks for hospital-acquired infections

\begin{tabular}{l|l|l|c}
\hline Benchmark & CLABSI & CAUTI & VAP \\
\hline NHSN (2010) & $1.1(1.1-1.2)$ & $1.5(1.4-1.5)$ & $1.3(1.2-1.4)$ \\
\hline INICC (2004-2009) & $5.9(5.7-6.2)$ & $7.1(6.9-7.3)$ & $18.4(17.9-18.8)$ \\
\hline
\end{tabular}

All rates are per 1,000 device-days NHSN National Healthcare Safety Network, INICC International Nosocomial Infection Control Consortium, CLABSI central line-associated bloodstream infection, CAUTI catheter-associated urinary tract infection, $V A P$ ventilator-associated pneumonia

infections (CLABSI) rates and a $17 \%$ reduction in surgical site infections (SSI) [13, 68]. Table 1 shows the National Health Safety Network (NHSN) and INICC benchmarks for various hospital-acquired infections [23].

Although nosocomial infections can be caused by a variety of organisms including bacteria, virus, fungi, and parasites, bacterial infections are the commonest. These agents may be commensals in the patient or may originate from an exogenous source and spread via cross infection. Hospital-acquired pathogens are often resistant to most antibiotics (multidrug resistant) or at times extremely drug resistant or pan drug resistant, thereby increasing the treatment costs, antibiotic use, and antibiotic resistance. This is evident from microbiology data demonstrating an increasing incidence of nosocomial infections that are caused by multidrug-resistant bacteria over the years [19, 86]. The common pathogens are gram-negative bacteria including Pseudomonas, Klebsiella, and Acinetobacter and gram-positive bacteria like methicillin-resistant Staphylococcus aureus (MRSA), coagulase-negative Staphylococci, and Enterococci. Invasive candidal infections also occur in those with indwelling catheters, lines or contaminated abdominal surgeries [66]. The other common nosocomial organisms are Clostridium difficile, vancomycin-resistant Enterococci, anaerobes, and Enterobacter.

Nosocomial infections result in an increased mortality and morbidity to the patients with a significant effect on the treatment cost due to the need for higher antibiotics and prolonged ICU and hospital length of stay. These infections are responsible for $4-56 \%$ of all death causes in neonates in developing countries and 11-25\% in the United States [46]. As per the World Health Organization (WHO) report, nosocomial infections result in direct financial losses of approximately $€ 7$ billion in Europe and $\$ 6.5$ billion in the United States.

\section{Risk Factors}

The risk factors for developing nosocomial infections are:

(a) Patient factors such as extremes of age, immunosuppression due to malignancy, acquired immunodeficiency syndrome (AIDS), patients requiring emergency admission to the intensive care unit (ICU), duration of stay more than 7 days, chronic illness like renal failure, diabetes mellitus, chronic liver disease, presence of indwelling catheters, ventilation, total parenteral nutrition, trauma, abdominal surgeries, and impaired functional status $[44,45]$

(b) Organizational factors such as the poor environmental hygiene inside the hospital or ICU, lack of efficient infection control measures, inadequate manpower such as an inadequate nurse to patient ratio or inadequate waste management staff, and inadequate equipment for patient use

(c) Iatrogenic factors such as ignorance regarding infection control practices, lack of training in infection control, etc. [41]

\section{Treatment and Prevention of Nosocomial Infections}

\section{Strategies for the Prevention of Nosocomial Infections}

As majority of the patient risk factors for developing nosocomial infections cannot be modified, care should be given for focused education and training to the hospital staff, by distribution of education materials regarding healthcareassociated infections and basic infection control policies including identifying the need of isolation, types of isolation, barrier nursing, hand 
hygiene, etc. [14] An infection control committee should be formed headed by an infection control nurse and hospital - infection control policies should be laid down. The infection control committee should be entrusted with the responsibility of formulating and implementing "care bundles" for common nosocomial infections that can be adopted from health organizations like CDC, WHO, etc. and modified as per hospital policy. Across the world, implementation of such "bundles of care" and adherence to these bundles have been proven to significantly reduce nosocomial infections, especially in the developing countries $[1,69]$. The infection control team should conduct audits and give necessary feedback regarding compliance with hand-washing and other infection control policies. [55].

An Antibiotic Stewardship Program should be initiated with a multidisciplinary team, with members such as an infectious disease specialist, a clinical pharmacist with training in infectious disease, a clinical microbiologist, an information system specialist, and an epidemiologist, with a policy for regulating higher antibiotic prescription. Review of practice of antibiotic prescription, ensuring environmental decontamination with surface cleaning, air filtration and decontamination of water source, increasing strength of healthcare personnel (improving nurse to patient ratio and increasing waste management staff), and regular training and feedback to hospital staff are some important measures that can be adopted at an institutional level for reducing the nosocomial infections inside the hospital. The treatment of common nosocomial infections and bundle of cares will be discussed under respective sections in the chapter.

\section{Nosocomial Pneumonia}

Previously nosocomial pneumonia was considered as a spectrum of high-risk diseases comprising of ventilator-associated pneumonia, non-ventilator-associated hospital-acquired pneumonia, and healthcare-associated pneumonia. The terminology "healthcare-associated pneumonia (HCAP)" was introduced by the
Infectious Diseases Society of America (IDSA) in 2005 for patients in the community to be considered at high risk for MDR pathogens similar to those associated with HAP. These patients, in spite of not being hospitalized, were still considered as high risk in virtue of their interaction with the healthcare system. Over years, increasing evidence suggested that this could be a false assumption that also led to inappropriate use of antibiotics [15, 37]. Probably this group of patients needs to be considered as a high-risk group when they present to the emergency department with communityacquired pneumonia. Hence the current guidelines do not consider HCAP as a part of HAP $[40,78]$. The current IDSA guidelines recommend the use of two mutually exclusive terms ventilator-associated pneumonia and hospitalacquired pneumonia - thereby avoiding the terminology of "non-ventilator-associated hospital-acquired pneumonia." The terminology has been explained in Fig. 1.

Nosocomial pneumonia (HAP and VAP) is the most common hospital-acquired infection in the developed world, with a prevalence of $22 \%$ [40]. VAP contributes almost $50 \%$ of all cases of nosocomial pneumonia and is a major cause of increased morbidity and mortality. The attributable mortality rates of VAP range from $13 \%$ to $15 \%$ across both developing and developed countries [57]. Although hospital-acquired pneumonia (HAP) is generally considered to be less severe than VAP, patients who develop complications of HAP have mortality rates similar to those of VAP. In the ICU, data suggests that treatment of VAP is the main reason for antibiotic usage, with more than $50 \%$ of antibiotic use in ICU being for VAP [83]. VAP also significantly prolongs ventilation days, hospital length of stay, and treatment costs as compared to patients who do not develop VAP.

\section{Definition of Ventilator-Associated Pneumonia}

Ventilator-associated pneumonia (VAP) is defined as pneumonia occurring after $48-72$ of intubation 


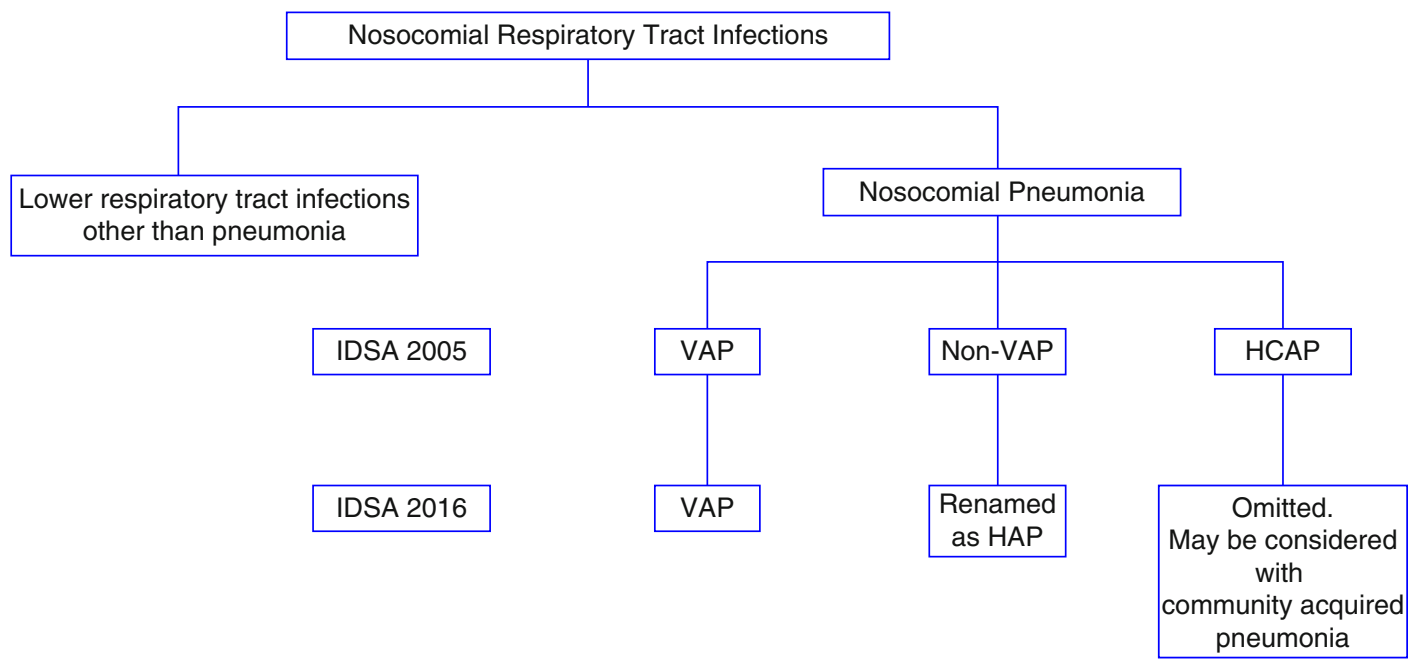

Fig. 1 Nosocomial pneumonia: terminology. IDSA Infectious Diseases Society of America, VAP ventilator associated pneumonia, $H C A P$ healthcare associated pneumonia

and ventilation, associated with a new or progressive infiltrate on chest X-ray along with fever, altered leucocyte count, and changes in sputum characteristics for which a definitive causative agent can be found [39]. Early VAP occurs in the initial days of ventilation (within 48-96 h) and is more likely to be caused by antibiotic-sensitive bacteria. Late VAP (occurring after 4 days) is likely caused by bacteria which are likely to be multidrug resistant. However, this distinction might not hold true always as patients who are hospitalized for more than 2 days prior to intubation will probably harbor multidrug-resistant bugs [31].

\section{Incidence of VAP}

VAP is the most common nosocomial infection in patients who are mechanically ventilated with rates of $10 \%$ being reported among patients admitted in multiple hospitals across the United States [31, 85]. The International Nosocomial Infection Control Consortium (INICC) data from the developing world suggests that the overall VAP rate was 12.2 per 1,000 ventilator days with a pooled crude excess mortality of $35.9 \%$ [68]. The incidence increases with duration of ventilation. The risk of VAP is highest during the initial days of ventilation $(3 \%$ per day), which gradually decreases over time ( $2 \%$ per day from fifth to tenth day and $1 \%$ afterward). Older data suggested that most of the VAP episodes occurred in the initial part of ICU stay itself (early VAP) probably because of the increased practices of short-term ventilation in majority of patients [27]. Recent studies however suggest the converse with an increase in the late VAP rates (as much as $66 \%$ of total VAP) [32].

The data on VAP is difficult to assimilate for surveillance reporting due to the technical issues in diagnosing VAP from radiologic criteria alone and in differentiating VAP from other conditions such as pulmonary edema or acute respiratory distress syndrome. Hence the CDC has laid down a set of epidemiological definitions called ventilator-associated events (VAEs). [11]. This is a surveillance system to prevent underreporting of the complications (including VAP) occurring in mechanically ventilated patients, irrespective of their origin or mechanism, and should not be used in the clinical management of patients.

Ventilator-associated events are defined for a period of 2 weeks and require patients to be ventilated for a minimum of 4 days, with at least 2 days of clinical stability, to be assessed for VAE. VAEs are further classified into ventilator- 
associated condition (VAC), infection-related ventilator-associated condition (IVAC), and ventilator-associated pneumonia (VAP) and defined as follows:

Ventilator-associated condition (VAC) is defined as 2 days of worsening oxygenation, assessed by an increase in PEEP requirement more than $3 \mathrm{~cm}$ of $\mathrm{H} 2 \mathrm{O}$ or an increase inFiO2 requirement more than 0.2 , after an initial clinical stability (of $48 \mathrm{~h}$ ) or improvement.

Any VAC associated with either a change in temperature or leucocyte count (fever $>38^{\circ} \mathrm{C}$ or hypothermia $<36{ }^{\circ} \mathrm{C}$, or leukocytosis $>12,000$ / $\mathrm{mm}^{3}$ or leukopenia $<4,000 / \mathrm{mm}^{3}$ ) AND that requires addition of a new antibiotic for at least 4 days is an infection-related ventilator-associated complication (IVAC).

An IVAC, with a positive microbiological test from respiratory tract specimens, is called possible VAP (PVAP).

A positive microbiological test is defined as a positive microbiological culture in specimens, meeting the threshold of quantitative or semiquantitative culture, without purulent respiratory secretions; OR a representative lower respiratory tract sample that is visibly purulent, but the positive culture does not meet the thresholds as per quantitative or semiquantitative criteria; OR positive pleural fluid culture or lung tissue culture or a positive test result for legionella or viruses implicated in respiratory diseases.

Organisms such as Candida species, coagulase-negative Staphylococcus (CONS), and Enterococcus species can be considered as positive microbiological test only if isolated from pleural fluid or lung tissue and not from sputum, endotracheal aspirates, bronchoalveolar lavage, or protected specimen brush specimens. Positive microbiological test of normal/respiratory flora should be ignored [11].

VAP is defined as a pneumonia occurring in a patient on ventilator for at least 2 calendar days before the onset of a VAE, with same duration of ventilation, AND the patient was on ventilator on the day of the event, or a day prior [11].

\section{Pathogenesis of VAP}

A complex interplay between host factors, microbiology of the oropharyngeal flora, and the presence of endotracheal tube is responsible for the development of VAP. This is summarized in Fig. 2.

After hospitalization and antibiotic administration, the normal flora of the upper respiratory tract is replaced by exogenous aerobic gramnegative flora due to alterations in host defense properties. These organisms colonize in the oropharynx from multiple sources (see Table 2). The normal cough reflex is hampered by the endotracheal tube, and these pathogens gain access to the lower respiratory tract through micro-aspiration along the endotracheal cuff, aided by the ventilator gas flow. The stomach is an important source of bacterial colonization. Change in the acidic $\mathrm{pH}$ of the stomach due to drugs favors colonization with these virulent bacteria, and with regurgitation of gastric contents, they pool in the oropharynx and reach the lower respiratory tract by micro-aspirations. The risks are further increased in the absence of adequate cuff seal or with multiple attempts of intubation. These virulent bacteria are usually difficult to treat owing to the thick biofilm that they produce alongside the endotracheal tube. The presence of this biofilm hampers antibiotic penetration and increases antibiotic use and antibiotic resistance [31, 39].

Although increased pharyngeal colonization with virulent bacteria, micro-aspiration, and biofilm formation all contribute to the risk of developing VAP, it is the host's immune response to these pathogens that determines whether VAP will develop or not. Immunosuppression is common in critically ill patients due to dysfunction of monocytes and T cells [76]. Apart from that, critically ill patients have an over expression of $\mathrm{C} 5 \mathrm{a}$ that leads to neutrophil dysfunction and reduced phagocytic activity, again predisposing them to severe infections [31]. Other contributory factors to the development of VAP include advanced age, emergency intubation for surgery or trauma, severity of illness and organ dysfunction, immunosuppressant drugs, previous antibiotic exposure, presence of 


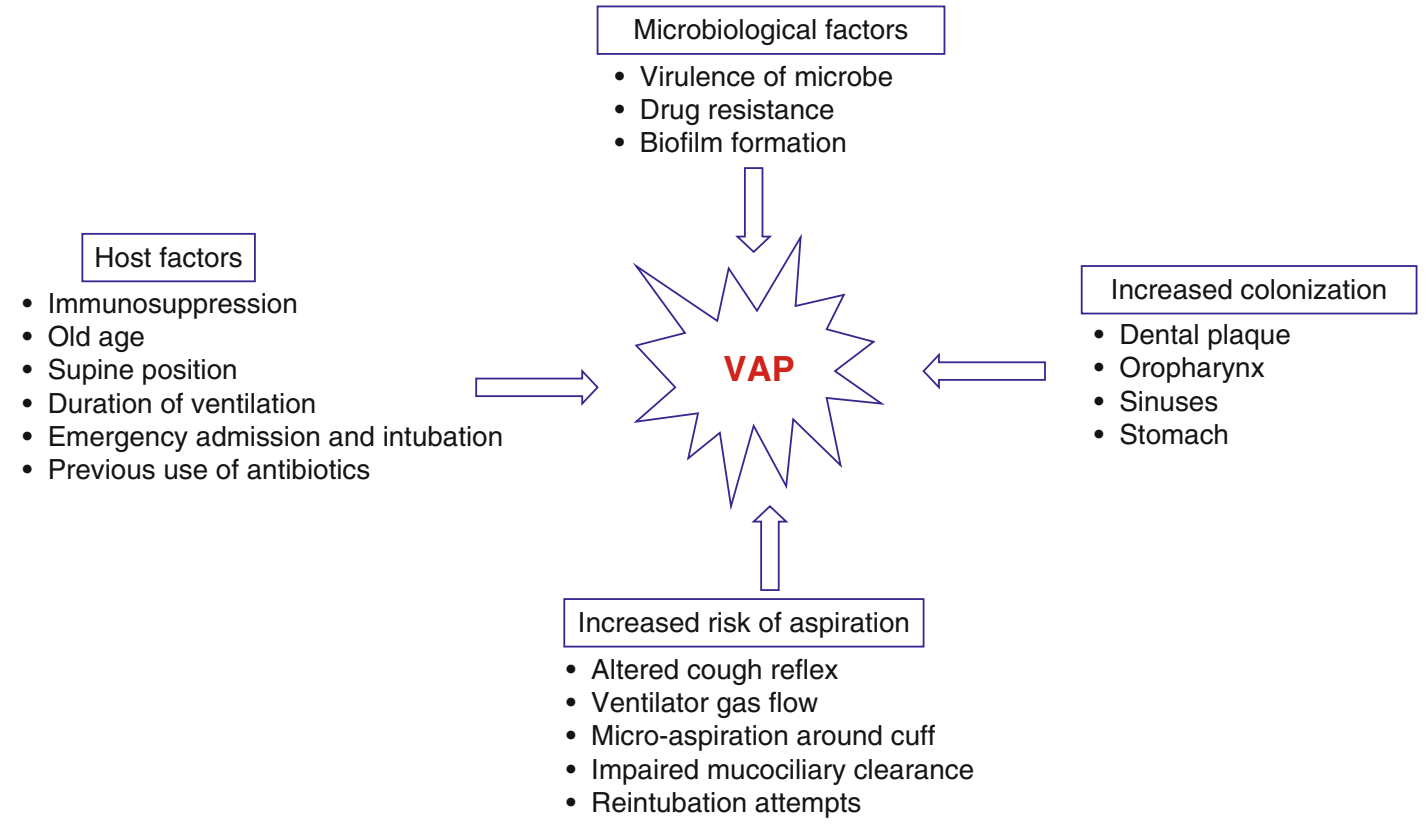

Fig. 2 Pathogenesis of ventilator-associated pneumonia (VAP)

Table 2 Sources of bacterial colonization in ventilated patients

\begin{tabular}{l}
\hline Dental plaque \\
\hline Oropharyngeal secretions \\
\hline Sinusitis \\
\hline Regurgitation of gastric contents into oral cavity \\
\hline $\begin{array}{l}\text { Cross contamination by healthcare providers (due to poor } \\
\text { infection control practices) }\end{array}$ \\
\hline
\end{tabular}

nasogastric tubes (resulting in sinusitis), and preexisting illness like diabetes mellitus, chronic lung disease, and chronic renal failure.

\section{Etiology of VAP}

The etiology for VAP varies between ICUs and hospitals which highlights the importance of knowing local infection and susceptibility patterns. The duration of hospital stays before intubation, length of ICU stays, and duration of ventilation are also significant as they determine the nature of flora causing VAP (see Table 3). VAP before 4 days (early-onset VAP) is often caused by microbes similar to the organisms causing community-acquired pneumonia like Streptococcus pneumoniae, Haemophilus influenzae, methicillin-sensitive $S$. aureus (MSSA), and susceptible Enterobacteriaceae [50]. Late-onset VAP is usually caused by microbes from the hospital environment. They are usually the aerobic gramnegative bacilli like Klebsiella, Pseudomonas, Acinetobacter, Enterobacter, and E. coli, while MRSA is rarely implicated [50]. The odds that they are multidrug resistant is high, and hence these infections are more difficult to treat. This difference between early and late VAP may not always be clinically relevant, and there are increasing reports of lack of difference in microbiology and mortality across both groups [21, 26]. Patients who are previously exposed to healthcare environment such as those who received antibiotics within the preceding 3 months, those who are currently hospitalized for more than 5 days, those who are on immunosuppressants, or those who have immunosuppressive states such as chronic renal failure, diabetes mellitus, AIDS, etc. are prone to multidrugresistant infections irrespective of the onset of VAP. 
Table 3 Microbiology of ventilator-associated pneumonia

\begin{tabular}{|c|c|}
\hline Onset of VAP & Etiology \\
\hline $\begin{array}{l}\text { Occurring within } 4 \text { days of } \\
\text { intubation (early VAP) }\end{array}$ & $\begin{array}{l}\text { Streptococcus } \\
\text { pneumoniae, } \\
\text { methicillin-sensitive } \\
\text { Staphylococcus aureus } \\
\text { (MSSA), Haemophilus } \\
\text { influenzae }\end{array}$ \\
\hline $\begin{array}{l}\text { Occurring after } 7 \text { days of } \\
\text { intubation (late VAP) }\end{array}$ & $\begin{array}{l}\text { Klebsiella, } \\
\text { Pseudomonas } \\
\text { aeruginosa, methicillin- } \\
\text { resistant } S \text {. aureus } \\
\text { (MRSA), Acinetobacter } \\
\text { spp. }\end{array}$ \\
\hline $\begin{array}{l}\text { Intravenous antibiotics } \\
\text { within the previous } \\
3 \text { months }\end{array}$ & \multirow{5}{*}{$\begin{array}{l}\text { Klebsiella, } \\
\text { Pseudomonas } \\
\text { aeruginosa, methicillin- } \\
\text { resistant } S \text {. aureus } \\
\text { (MRSA), Acinetobacter } \\
\text { spp. }\end{array}$} \\
\hline $\begin{array}{l}\text { ARDS preceding the onset } \\
\text { of VAP }\end{array}$ & \\
\hline Septic shock at presentation & \\
\hline $\begin{array}{l}\text { Hospitalization for } 5 \text { days or } \\
\text { more prior to onset of VAP }\end{array}$ & \\
\hline $\begin{array}{l}\text { VAP developing in those } \\
\text { who are currently receiving } \\
\text { renal replacement therapy }\end{array}$ & \\
\hline
\end{tabular}

$V A P$ ventilator-associated pneumonia, MSSA methicillinsensitive Staphylococcus aureus, MRSA methicillinresistant $S$. aureus, ARDS acute respiratory distress syndrome

\section{Diagnosis of VAP}

VAP is diagnosed in patients who are being ventilated or was on a ventilator recently and develops signs of infection such as fever or hypothermia, leukocytosis or leukopenia, and worsening in gas exchange along with the appearance of new infiltrates on radiologic imaging and changing nature (increase in purulence) of the tracheobronchial secretions [39]. These signs are highly nonspecific and may be also associated with various noninfectious causes. Moreover, the sensitivity and specificity of routine ICU X-rays is much lower than the conventional X-rays. Interobserver variability in interpreting X-ray findings also affects their accuracy as a diagnostic tool. Hence the diagnosis of VAP in ICU lacks sensitivity and specificity and may result in both over diagnosis or underdiagnosis. However, if the clinical suspicion of pneumonia is high, empiric antibiotics should be administered immediately as delay in antimicrobial treatment leads to increased mortality $[38,49]$.

To aid in the diagnosis and to rationalize the use of empirical antibiotic therapy for VAP, a clinico-radiologic criterion was proposed - the Clinical Pulmonary Infection Score (CPIS). The CPIS (Table 4) consists of six clinical and laboratory parameters with scores range from 0 to 12 . A score $\geq 6$ has a sensitivity of $72 \%$ and a specificity of $85 \%$, for the presence of VAP [60, 89]. Although seemingly simple and straightforward, calculation of CPIS score also varies substantially from observer to observer, hereby limiting its routine use in clinical trials [89]. The current IDSA guidelines suggest the use of clinical criteria rather than CPIS score for initiating and stopping of antibiotics [40].

\section{Microbiological Methods for Diagnosis of VAP}

A microbiologic diagnosis can be made by gram staining and culture of the tracheal aspirate or lower respiratory secretions obtained by direct/ non-direct bronchoscopic alveolar lavage (BAL). Bronchoscopic techniques like BAL, mini-BAL, and protected specimen brush (PSB) specimens provide reliable lower respiratory tract samples, and quantitative cultures of these samples may help to differentiate colonization from true infections. Technically it has the advantage of identifying the pathogens correctly, leading to less antibiotic exposure and thereby minimizing antibiotic resistance. However, bronchoscopy and sample collection require expertise and still result in false negative reports. Blind sampling requires less expertise and infrastructure and is easy to perform. However, blind sampling is likely to produce false positive results with colonizing organisms, thereby increasing inappropriate antibiotic use and promoting antibiotic resistance. The available data remains conflicting with no benefits of one method over the other with respect to mortality, length of ICU stay, and mechanical ventilation days $[10,75]$. The IDSA recommends blind methods of sample collection, while the 
Table 4 Clinical pulmonary infection score (CPIS)

\begin{tabular}{|c|c|c|c|}
\hline Parameter & 0 & 1 & 2 \\
\hline $\begin{array}{l}\text { Temperature (in degree } \\
\text { Celsius) add } 0.5^{\circ} \text { for oral } \\
\text { temperature }\end{array}$ & $36.5-38.4$ & $38.5-38.9$ & More than 39.0 , or less than 36.5 \\
\hline Leucocyte count in blood & $4000-11,000$ & $\begin{array}{l}\text { Leukopenia less than } \\
4000 \text { or leukocytosis } \\
\text { more than } 11000\end{array}$ & $\begin{array}{l}\text { leucopenia less than } 4000 \text { or leukocytosis } \\
\text { more than } 11000 \text { and Band forms more } \\
\text { than } 50 \% \text {, }\end{array}$ \\
\hline Tracheal secretions & Absent & Non-purulent & Purulent \\
\hline $\begin{array}{l}\text { Culture results } \\
\text { (endotracheal aspirate) }\end{array}$ & $\begin{array}{l}\text { No or mild } \\
\text { growth }\end{array}$ & Moderate or florid growth & $\begin{array}{l}\text { Moderate or florid growth AND } \\
\text { pathogen consistent with gram stain }\end{array}$ \\
\hline $\mathrm{PaO} / \mathrm{FiO}_{2}$ & $\begin{array}{l}>240 \text { or } \\
\text { ARDS }\end{array}$ & & $<240$ and no ARDS \\
\hline Infiltrate on CXR & No infiltrate & Diffuse or patchy & Localized \\
\hline
\end{tabular}

Table 5 Threshold values for cultured specimens used in the diagnosis of pneumonia

Bronchoalveolar lavage: more than $10^{4}$ colony-forming unit $/ \mathrm{ml}$

Protected specimen brush: more than $10^{3}$ colony-forming unit $/ \mathrm{ml}$

Nondirected bronchoalveolar lavage obtained from (blind) specimens: more than $10^{4}$ colony-forming unit $/ \mathrm{ml}$ Endotracheal aspirate: more than $10^{5} \mathrm{CFU} / \mathrm{ml}$

Open lung biopsy/transthoracic or transbronchial biopsy: more than $10^{4}$ colony-forming unit/g tissue

European guidelines recommend bronchoscopicdirected methods [40, 78]. The threshold values for cultured specimens recommended by CDC for the diagnosis of pneumonia are mentioned in Table 5.

\section{Biomarkers for Diagnosing VAP}

Numerous biomarkers for infection/inflammation have been studied in VAP including erythrocyte sedimentation rate (ESR), C-reactive protein (cRP), procalcitonin, pro-adrenomedullin, LPS-binding protein, soluble-triggering receptor expressed on myeloid cells (sTREM-)1, presepsin, etc. Other than ESR, cRP, and procalcitonin, the use of other biomarkers is not widely practiced out of research field [74]. Procalcitonin, a precursor hormone of calcitonin, is actively produced by neuroendocrine cells in the lung and intestine on exposure to bacterial endotoxin and inflammatory cytokines. The level peaks at $6 \mathrm{~h}$ and may aid in early identification of infections as compared to blood culture. Procalcitonin is not useful in cases of viral or fungal infections and in cases of localized bacterial infections. It is also elevated in noninfectious conditions such as burns, major surgery, end-stage renal failure, etc. [84]. Procalcitonin testing is expensive and serial measurements make it even more expensive. Based on the current data, procalcitonin levels should not be used to rule out an infection or influence the decision of antibiotic initiation. The main role of procalcitonin is in its role as a guide for early stoppage of antibiotics, thereby preventing unwanted exposure to antibiotics $[9,84]$. The current guidelines do not recommend the use of these biomarkers over clinical criteria for a diagnosis of VAP [40, 78].

\section{Antimicrobial Treatment}

IDSA recommends coverage for methicillinsensitive Staphylococcus aureus and gramnegative bacilli including pseudomonas for patients with suspected VAP, pending culture and sensitivity reports [40]. MRSA coverage is not usually required, unless there is an increased risk for MDR organisms such as recent antibiotic exposure, septic shock, acute respiratory distress 
syndrome (ARDS) prior to the current episode of VAP, acute kidney injury requiring renal replacement therapy, or in case of high infection rates of MRSA in the hospital, i.e., $>10-20 \%$. In patients without risk factors for gram-negative MDR infection, such as those without any structural lung disease or those who have not received antibiotics in recent past, a single antipseudomonal agent that also covers MSSA will be appropriate. Only in patients with underlying structural lung disease like bronchiectasis or cystic fibrosis or those having higher risk for MDR infection, dual antipseudomonal coverage should be given [40]. Recommended empirical antibiotics are those with antipseudomonal and MSSA activity such as ceftazidime, cefepime, piperacillintazobactam, fluoroquinolones such as levofloxacin, carbapenems such as meropenem or imipenem, etc. Aminoglycosides are not recommended as monotherapy for VAP. In case MRSA is suspected, linezolid or vancomycin may be used. With the increased incidence of infections due to MDR gram-negative pathogens, there has been a resurgence of polymyxins in the treatment of VAP. They may be particularly useful in places with increased baseline MDR Acinetobacter rates [40] and for empiric therapy in patients with septic shock or high risk such as neutropenic patients or those who have hypersensitivity to beta-lactams. Current evidence suggests that different doses or dosage schedules might be required for various bacteria, depending on the pharmacokinetic/pharmacodynamic parameters [28]. The IDSA guidelines recommend the addition of nebulized colistin along with intravenous route for managing VAP [40]. Regarding newer antibiotics, daptomycin is inactivated in the lungs and hence is not recommended for VAP. Tigecycline monotherapy in the doses as per the label is not recommended for HAP or VAP [40, 78]. Doxycycline and fosfomycin have not been studied for hospital-acquired MRSA as standalone treatments $[64,73]$. Antibiotics should be changed according to culture and sensitivity reports and may be administered for a total duration of 7 days, or fewer, perhaps guided by procalcitonin levels. The European guidelines for VAP recommend a total treatment duration of
7-8 days for all immunocompetent hosts in the absence of complications such as empyema, lung abscess, or necrotizing pneumonia, if initial empiric therapy was adequate and their response to treatment has been good irrespective of the microbiological etiology. Patients infected with Pseudomonas, carbapenem-resistant Enterobacteriaceae, and Acinetobacter, those on antibiotics such as tigecycline and colistin, and immunocompromised hosts will require a prolonged duration of treatment [78].

A simplified algorithm for antibiotic selection is shown in Fig. 3

\section{Guidelines for Management of Nosocomial Pneumonia}

Guidelines for managing VAP and HAP were published by the ATS and IDSA in 2016, while the European Respiratory Society/European Society of Intensive Care Medicine/European Society of Clinical Microbiology and Infectious Diseases guidelines were published in 2017. While addressing nosocomial pneumonia including HAP and VAP, both guidelines concur with each other except for a few points. The ATS guidelines do not make any new recommendations regarding VAP prevention and encourage the use of clinical criteria to decide on initiation and discontinuation of antibiotics rather than use of Clinical Pulmonary Infection Score (CPIS) score. The ATS guidelines recommend the usage of noninvasive or minimally invasive techniques for microbiological investigations of VAP. Risk factors for MDR pathogens are described by ATS as prior hospitalization and organ failure such as septic shock ARDS and requirement of dialysis prior to VAP onset. They recommend combination therapy for target therapy and set a duration of treatment for HAP and VAP as 7 days. The European guidelines mention prevention strategies for VAP but do not make any recommendation on the use of chlorhexidine for selective oropharyngeal decontamination. The European guidelines introduce the concept of "low probability of HAP" and suggest the usage of CPIS score to identify the same. They endorse invasive sampling over 


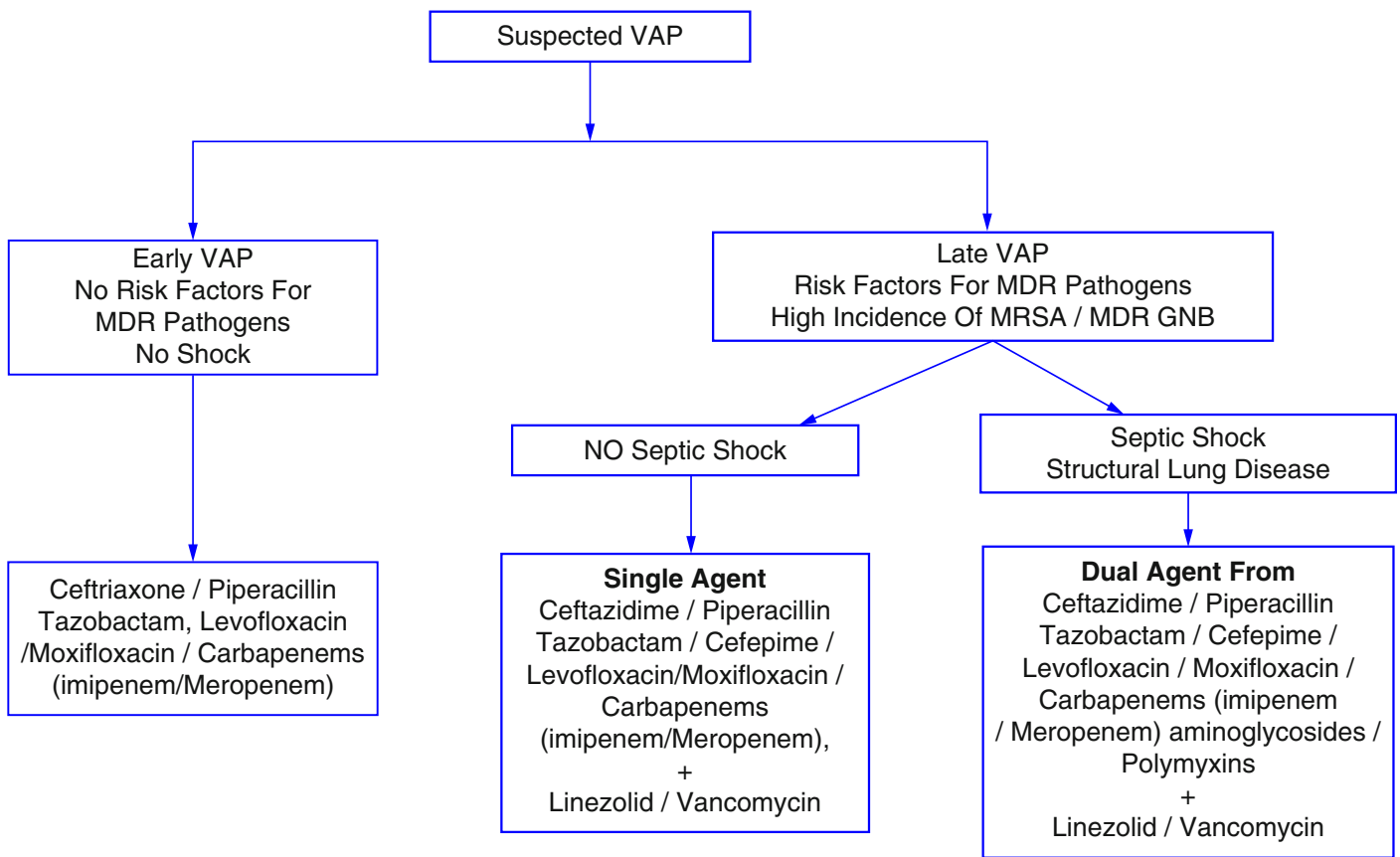

Fig. 3 An algorithm for selection of empirical antibiotics for ventilator-associated pneumonia. $V A P$ ventilator associated pneumonia, $M D R$ multi drug resistance, $M R S A$ methicillin resistant Staph Aureus, GNB gram negative bacilli

noninvasive sampling, as it might help to avoid overdiagnosis and unnecessary antibiotic exposure. The risk of MDR pathogens is described based upon local prevalence rates of MDR organisms and presence of septic shock. Although they recommend 7 days of treatment, they suggested prolonged treatment for selected patients. Both guidelines agree on the need of appropriate empiric antibiotic treatment, the need for de-escalation, and the need to minimize antibiotic exposure $[40,54,78,79]$.

\section{Pharmacokinetics of Antibiotics in the Lung}

The antimicrobial drug concentration in the lung is the most important factor that determines the efficacy of the antibiotic treatment. Drugs delivered reach the lung parenchyma by bulk flow, permeation, active transport, and passive diffusion [81]. Patient factors such as parenchymal inflammation, volume of distribution, renal function, and drug factors such as water solubility, tissue penetration, molecular weight, inactivation of drug in local site, etc. are important factors in deciding the further efficacy of these drugs. Hydrophilic drugs like beta-lactams, aminoglycosides, and colistin attain less concentrations in the lung even after administering of therapeutic dose, while linezolid, fluoroquinolones, and macrolides concentrate well inside the lung. Hence the pharmacokinetic (pk) and pharmacodynamic (pd) parameters of drugs should be kept in mind while determining loading dose, dosing frequency, and dosing route. Alternate routes such as nebulization may be tried as an additional measure to improve the lung deposition of the antibiotics [36].

\section{Non-resolving Ventilator-Associated Pneumonia}

The exact time frame of when to expect resolution of symptoms of VAP after initiation of treatment is unclear and varies upon the symptoms or signs that are being monitored for resolution. The lack of improvement in clinical condition and/or clinical parameters such as fever, tachypnea, oxygenation, etc. after initiation of treatment can be either due to poor response to treatment/persistence of 
infection or due to a secondary infection. Typically, non-resolving pneumonia is common in elderly patients or in those with comorbidities, underlying immunosuppression, chronic lung disease, or infection with virulent/drug resistant pathogen. Treatment factors such as inappropriate initial therapy (either drug or its dose, route, frequency, and duration) are other important factors responsible for VAP. Workup for non-resolving pneumonia should be undertaken, including microbiological workup for MDR pathogens and imaging for complications such as lung abscess or empyema, while ruling out noninfectious causes of fever and radiologic infiltrates. Once an infective etiology is confirmed, optimizing antibiotics as per the $\mathrm{pk} / \mathrm{pd}$ principles with a hike in antimicrobial coverage will be needed to manage non-resolving pneumonia [51].

\section{Prevention of VAP}

Infection control programs form the most crucial step in the prevention of VAP [69]. VAP rates can be reduced by proper decontamination of ventilatory equipment and practice of infection control measures during care of the mechanically ventilated patient. A brief outline of the steps to reduce VAP is given below.

\section{General Infection Control Measures}

1. Adherence to the five moments of hand hygiene as recommended by the World Health Organization (WHO) [88]. Avoiding intubation and re-intubation by the judicious use of noninvasive ventilation and high-flow nasal oxygen helps reduce the risk of development of VAP.

2. Preferring the use oral route than nasal route for intubation, thereby reducing the chances of nosocomial sinusitis and VAP.

3. Avoid routine stress ulcer prophylaxis as alteration in gastric $\mathrm{pH}$ is associated with increased microbial colonization in the stomach.

4. Enteral feeding reduces the gut translocation of endogenous bacteria and reduces bacteremia. Caution should be taken to avoid overdistension of the stomach and monitor gastric residual volumes if there are signs of feed intolerance.

5. Daily oral hygiene with $0.12-2 \%$ chlorhexidine gel reduces the pathological colonization of oral flora. Its role is supported by evidence of multiple meta-analyses of randomized controlled trials which are open-labelled trials [47]. Role of selective decontamination of the gut is controversial in areas with high antibiotic resistance.

\section{Reduction in Aspiration Pass the Cuff}

Elevation of the head end of the bed by $30-45^{\circ}$ has shown to reduce VAP rates significantly and is recommended by many professional societies [58].

Continuous low-pressure suction of the subglottic secretions above the endotracheal cuff is useful [52].

Silver-coated endotracheal tubes may prevent bacterial colonization and biofilm formation though the current evidence is weak. [53]

\section{VAP Bundle}

The term "bundles" in critical care refers to collective group of practice statements, each with high level of evidence in itself; when practiced together, they result in better patient outcome by the consistent delivery of these practices and avoidance of individual preferences or practices [34, 43]. Infection surveillance, hand hygiene, semi-recumbent positioning, early extubation, ensuring adequate cuff pressure, and continuous subglottic suctioning have been proven to be simple and efficient methods that help to reduce VAP rates significantly [17]. The initial VAP bundle suggested by IHI comprised of five components: head end elevation of bed, daily interruption of sedation combined with assessment of the likelihood of weaning, prophylaxis for stress ulcer and deep vein thrombosis, and daily oral care with chlorhexidine [33]. Table 6 represents the suggested practice from Scottish intensive care society [18]. They differ from the classical Institute for Healthcare Improvement (IHI) VAP bundle by not suggesting peptic ulcer prophylaxis or DVT prophylaxis as they have no direct relation with VAP rates. 
Table 6 Suggested practices for VAP reduction

\begin{tabular}{|c|c|c|c|c|}
\hline $\begin{array}{l}\text { SL. } \\
\text { NO }\end{array}$ & Intervention & Rationale & Caution & $\begin{array}{l}\text { Level of } \\
\text { evidence }\end{array}$ \\
\hline 1 & Avoid intubation if possible & $\begin{array}{l}\text { Trials with noninvasive } \\
\text { ventilation (NIV) have shown } \\
\text { that NIV improves outcomes } \\
\text { in select group of patients such } \\
\text { as acute respiratory failure due } \\
\text { to an COPD exacerbation and } \\
\text { cardiogenic pulmonary edema }\end{array}$ & $\begin{array}{l}\text { Failure of NIV is associated } \\
\text { with high mortality rates }\end{array}$ & High \\
\hline \multirow[t]{3}{*}{2} & \multirow{3}{*}{$\begin{array}{l}\text { Daily sedation interruption } \\
\text { with stopping of sedation if } \\
\text { deemed unnecessary, daily } \\
\text { awakening and daily } \\
\text { spontaneous breathing trials }\end{array}$} & \multirow{3}{*}{$\begin{array}{l}\text { Continuous infusion of } \\
\text { sedatives increases the context } \\
\text { sensitivity half-lives of these } \\
\text { drugs and thereby increases } \\
\text { the length of ventilation }\end{array}$} & Maintain analgesia & \multirow[t]{3}{*}{ High } \\
\hline & & & Avoid ventilator asynchrony & \\
\hline & & & $\begin{array}{l}\text { Avoid in patients who are } \\
\text { paralyzed, those on end-of-life } \\
\text { care, those with raised ICP, } \\
\text { those with ARDS, and those } \\
\text { with ongoing therapeutic } \\
\text { hypothermia }\end{array}$ & \\
\hline 3 & $\begin{array}{l}\text { Using endotracheal tubes with } \\
\text { subglottic secretion drainage } \\
\text { ports }\end{array}$ & $\begin{array}{l}\text { Subglottic aspiration of } \\
\text { oropharyngeal secretions may } \\
\text { reduce aspiration and risk of } \\
\text { airway colonization }\end{array}$ & $\begin{array}{l}\text { The recommendation does not } \\
\text { suggest re-intubation in those } \\
\text { who are intubated with } \\
\text { endotracheal tubes without } \\
\text { subglottic suction }\end{array}$ & Moderate \\
\hline 4 & $\begin{array}{l}\text { Elevate the head of the bed to } \\
30-45^{\circ}\end{array}$ & $\begin{array}{l}\text { Patient should be nursed with } \\
\text { head end in } 30-45^{\circ} \text { and } \\
\text { avoiding flat positioning. This } \\
\text { reduces gastroesophageal } \\
\text { reflux and VAP rates }\end{array}$ & $\begin{array}{l}\text { Caution to be maintained } \\
\text { during care of } \\
\text { hemodynamically unstable } \\
\text { patients, those with spinal } \\
\text { trauma and pelvic injuries }\end{array}$ & Low \\
\hline \multirow[t]{3}{*}{5} & \multirow{3}{*}{$\begin{array}{l}\text { Daily oral care with } \\
\text { chlorhexidine }(0.12-2 \%) \\
\text { solution }\end{array}$} & \multirow{3}{*}{$\begin{array}{l}\text { Reduction of the } \\
\text { oropharyngeal colonization }\end{array}$} & Evidence is moderate to low & \multirow[t]{3}{*}{ Moderate } \\
\hline & & & $\begin{array}{l}\text { Can cause chemical } \\
\text { pneumonitis and ARDS if } \\
\text { aspirated }\end{array}$ & \\
\hline & & & $\begin{array}{l}\text { May increase mortality in } \\
\text { patients who are not ventilated }\end{array}$ & \\
\hline
\end{tabular}

$V A P$ ventilator-associated pneumonia, NIV noninvasive ventilation, COPD chronic obstructive lung disease, ICP intracranial pressure, $A R D S$ acute respiratory distress syndrome

Similarly, the implementation of a bundle for VAP as proposed by the International Nosocomial Infection Control Consortium (INICC) also led to substantial reduction in VAP rates in multiple countries including India, Kuwait, Saudi Arabia, etc. [1, 2, 56]. The bundle proposed by the INIC consortium included the following elements:

1. Adherence to guidelines for hand hygiene

2. Patient nursing in a semi-recumbent position, with head of the bed elevated at $30-45^{\circ}$

3. Use of weaning protocols and daily assessment of readiness to wean

4. Regular oral care with chlorhexidine
5. Minimization of the duration of mechanical ventilation and use of noninvasive ventilation if feasible

6. Preferable the orotracheal route instead of nasotracheal route for intubation

7. Endotracheal cuff pressure monitoring and attempts to keep it at least $20 \mathrm{~cm} \mathrm{H} 2 \mathrm{O}$

8. Care of ventilator circuits and removal of condensates from circuits while keeping the ventilator circuit closed

9. Avoiding scheduled changes of ventilator circuits and changing them only if they are visibly soiled or malfunctioning

10. Prevention against gastric overdistension

11. Avoidance of stress ulcer prophylaxis 
12. Reusable respiratory equipment rinsed properly in sterile water

13. Direct observation at regular scheduled intervals for hand hygiene compliance, duration of ventilation, and ventilation ratio use, with the aid of a structured observation tool

Similar to the INICC study, a Spanish group reported successful reduction of their VAP rates by more than half with the implementation of a VAP bundle among ICUs across the country [3]. The bundle they used is similar to other VAP bundles and notably avoided the DVT and peptic ulcer prophylaxis of the IHI recommendation [4]. They had seven mandatory recommendations including staff training in airway management, hand hygiene in airway management, monitoring cuff pressure, chlorhexidine oral care, positioning in bed, striving to reduce ventilator days, and discouraging scheduled changes of ventilator circuits. They also added "highly recommended measures" such as selective decontamination of the digestive tract, subglottic suctioning, and short-course antibiotics for patients intubated with altered sensorium. The data published seemed robust and the reduction in VAP rates was sustained and significant.

These data suggest that VAP bundles are pragmatic, are easy to implement and adhere to, and are effective in reducing the VAP rates substantially across the world including developed and developing countries. Adapting evidence-based VAP bundles that are tailor-made to suit the prevailing practices and hospital policies does not affect the effectiveness of the program $[1,2,56]$.

\section{Non-ventilated Hospital-Acquired Pneumonia (NV-HAP) or Hospital- Acquired Pneumonia (HAP)}

With an increased awareness against VAP and with active infection control measures, the incidence of VAP is on a declining trend. There has been an increased incidence in HAP due to an increased use of noninvasive devices for respiratory support such as noninvasive ventilation and high-flow nasal oxygen [65]. Currently HAP is one of the leading causes of nosocomial infections that in turn leads to prolonged hospital stay and increased treatment costs. A recent study found that the incidence of HAP is 3.63 per 1000 patient days, occurring in both wards and the intensive care units [25].

HAP is classified into ICU acquired and non-ICU acquired HAP, with ICU acquired HAP having an increased incidence of MDR pathogens increased incidence of septic shock, and worse outcomes as compared to non-ICU HAP [59]. The term "non-ICU acquired pneumonia (NIAP)" has been recently proposed and refers to a specific subset of HAP patients who developed pneumonia outside ICU and has an estimated incidence of $1.6-3.7$ cases per 1000 admissions [62].

HAP differs from VAP with respect to the microbiology, diagnostic investigations, and mortality. The microbiological diagnosis is by culture of a pathogen identified from a representative sputum sample. There are no data to suggest invasive sampling techniques like bronchoscopy over simple sputum collection; rather some data suggest that they may be harmful and do not improve outcomes [29]. The use of rapid diagnostic methods such as polymerized chain reaction based technologies in HAP has yielded promising results especially in the choice of antibiotics and detection of antibiotic resistance. However further studies are needed to confirm the benefits of such systems over the possible disadvantages such as false diagnosis of colonization [65].

The microbiology of HAP differs from VAP, and there seems to be an increased incidence of S. Pneumoniae and respiratory viruses and a lower incidence of MDR gram-negative pathogens [59]. The ATS/IDSA guidelines recommend antipseudomonal therapy for most patients with HAP. This may lead to unnecessary use of broad spectrum antibiotic therapy [22]. The ERS guidelines suggest that antipseudomonal treatment is not necessary for initial empiric treatment of most patients with HAP, in the absence of risk factors or septic shock [78]. Thus, HAP patients need to be treated based on factors such as local epidemiology, 
surveillance cultures, presence or absence of MDR risk factors, and septic shock $[59,65]$.

\section{Catheter-Associated Urinary Tract Infections (CAUTI)}

Infections involving any part of the urinary system, from the urethra to kidney, are labelled as urinary tract infections. They comprise more than one third of all nosocomial infection. In the intensive care units, UTI comprises of $8-21 \%$ of all nosocomial infections and is the third most common nosocomial infection occurring in the ICU [12]. ICU patients require a catheter for reasons such as immobility, strict intake output charting, etc. and retain it for prolonged duration. Each catheter day is associated with a 3-7\% increase in the risk of acquiring a catheter-associated urinary tract infection (CAUTI).

\section{Definition}

The CDC guidelines classify CAUTI as symptomatic urinary tract infection or asymptomatic urinary tract infection as follows:

CAUTI is an infection occurring in a patient with an indwelling catheter of more than $48 \mathrm{~h}$ duration before the event, with the catheter remaining in situ or removed $24 \mathrm{~h}$ prior at the time of the event. Signs and symptoms of infection such as fever, suprapubic tenderness, loin pain, and - in those patients without the catheter - increased urinary frequency, urgency, and dysuria and a significant bacteriuria should be present [12]. Significant bacteriuria is defined as a urine culture with no more than two species of organisms identified, of which at least one of which is a bacterium which has a colony-forming unit count more than $10^{5} \mathrm{CFU} / \mathrm{ml}$ [12]. The most common pathogens associated with CAUTI are Enterobacteriaceae. In the setting of ICUs, Candida, Enterococcus, Pseudomonas, Klebsiella, and E. coli become increasingly prevalent and are often drug resistant [16].

\section{Risk Factors}

CAUTI as well as other nosocomial infections prolongs hospital stay, increases treatment cost, and increases mortality. As with an endotracheal tube for VAP, the indwelling catheter is the main risk factor for UTI. Other risk factors include female sex, severity of current illness, age greater than 50 years, presence of diabetes mellitus, altered RFT with serum creatinine level more than $2 \mathrm{mg} / \mathrm{dL}$, location of catheter insertion, nonadherence to aseptic precautions of catheter care, etc. [16].

Laboratory examination will demonstrate pyuria irrespective of symptoms and urine WBC $>10$ cells/microL. Quantitative urine $\mathrm{WBC}>10$ cells/microL has low sensitivity but retains high specificity for the likelihood of getting a positive microbiological culture.

A proper sample of urine should be sent for culture when CAUTI is for obtaining culture results. Samples should be collected from the "needleless site" after applying aseptic precautions or with a needle from the aspiration port. The idea of changing the catheter before sample collection has been suggested in some studies but currently cannot be recommended [71].

\section{Management of Nosocomial CAUTI}

The empiric antimicrobial therapy for CAUTI depends on the presentation, i.e., whether they are symptomatic/asymptomatic and also upon the complications if any. Antibiotics for asymptomatic bacteriuria do not prevent the progression to symptomatic CAUTI nor its complications. As the risk of antibiotic resistance is high, patients with asymptomatic bacteriuria are usually not treated with antibiotics except in pregnancy and in patients undergoing surgical procedures of the lower urinary tract [48]. For symptomatic bacteriuria, the choice of antibiotic will depend on patient's risk factors for MDR infection and ongoing antibiotics. A 7- to 14day duration of intravenous antibiotic therapy is generally advocated and can be switched to oral 
route as per the sensitivity reports if the patient can tolerate oral medications [30].

Candiduria is a common occurrence among hospitalized patients, with Candida being isolated from almost one third of the total samples among hospitalized patients. Candiduria with symptoms and signs of infection including fever, leukocytosis or leukopenia, shock, etc. should be evaluated for disseminated candidiasis. Treatment for otherwise asymptomatic candiduria is not required except in the high-risk population such as neutropenia or urinary tract instrumentation. Imaging should be obtained in patients with diabetes mellitus or urinary tract abnormalities in case of persistent candiduria as they have a high risk for developing fungal balls.

Treatment should be guided by the culture and sensitivity reports. Fluconazole $200-400 \mathrm{mg}$ daily is recommended for susceptible strains for a total duration of 7-14 days. Fluconazole-resistant strains should be treated with amphotericin B (0.3-0.6 $\mathrm{mg} / \mathrm{kg}$ per day) for 7 days. Lipid formulations of amphotericin $\mathrm{B}$ do not penetrate the kidney and cannot be used for the treatment of fungal CAUTI. The data on efficacy of echinocandins is still evolving, and the preliminary data shows clearance of candiduria with micafungin. Further data is required for making any recommendation [61].

\section{Prevention of CAUTI and CAUTI Bundle}

Strategies for reducing CAUTI include strict aseptic techniques including hand hygiene for insertion and maintenance of catheters and maintaining a closed drainage system, monitoring the insertion of urinary catheters for appropriate indications, development of CAUTI bundles [35] (Table 7) for placement, daily check list, early removal, encouraging other alternatives such as intermittent catheterization, and condom catheter. A recently conducted study in the United States demonstrated that a CAUTI bundle could reduce the catheter use and CAUTI rates in non-ICU acute care settings [70].

Other methods proposed to reduce the incidence of CAUTI were to use urinary catheters coated with antibiotics or to use urinary catheters with silver impregnated in it. Silver compound
Table 7 Catheter-associated urinary tract infection bundle

Avoid insertion of unnecessary catheters

Insert only under strict aseptic precautions

Strictly maintain catheter care daily (hand hygiene, closed drainage)

Daily review the necessity of catheter and remove it immediately once deemed unnecessary

Provide feedbacks to the units regarding catheter usage and CAUTI rates

Identify gaps in knowledge and address them

CAUTI catheter-associated urinary tract infection bundle

was found to reduce biofilm formation on the catheter significantly. However, the use of both types of catheter was not associated with a reduction in UTI rates or any other meaningful benefit [63].

\section{Surgical Site Infection}

Surgical site infections (SSIs) are those occurring at the incision site and/or extending to deeper tissue spaces or adjacent organs within 30 days of a surgery or within 90 days if the procedure involved prosthetic material implants. They are further classified into superficial SSI, deep SSI, and organ/space SSI (Table 8) [8].

These are the most common healthcareassociated infections in patients undergoing surgery, with an incidence of about $38 \%$ [87]. Studies have estimated that more than half of these infections are preventable, if appropriate measures were taken [80]. The most common organisms responsible for SSI are Staphylococcus aureus (MRSA and MSSA), E. coli, coagulase-negative Staphylococci (CONS), Pseudomonas, etc. [77]. The INICC data from developing countries shows a significantly higher incidence of SSI, as compared to the data from developed countries. The incidence rates reported by the INICC group are $2.6 \%$ after hip prosthesis, $4.5 \%$ after cardiac surgeries, $2.7 \%$ in abdominal hysterectomy, $4.1 \%$ in other abdominal surgery, and $12.9 \%$ after ventricular shunt [67].

Patients at risk include those who are elderly patients; those with history of skin or soft tissue infection, recent radiotherapy, diabetes, obesity, alcoholism, and preoperative hypoalbuminemia; 
Table 8 Classification of surgical site infection

\begin{tabular}{l|l}
\hline Superficial & $\begin{array}{l}\text { Systemic signs of infection with the } \\
\text { incisional wound infection limited to the } \\
\text { skin and subcutaneous tissue }\end{array}$ \\
\hline $\begin{array}{l}\text { Occurs within 30 days of surgery. } \\
\text { Diagnosis is made by the evidence of } \\
\text { infection such as purulent discharge from } \\
\text { wound site, with an organism identifies } \\
\text { from culture, or by clinical diagnosis of } \\
\text { debridement made by a surgeon }\end{array}$ \\
\hline Deep SSI & $\begin{array}{l}\text { Systemic signs of infection with } \\
\text { involvement of the deeper soft tissues }\end{array}$ \\
\cline { 2 - 2 } & $\begin{array}{l}\text { Occurs within 30 days of surgery or } \\
\text { 90 days in case of prosthesis surgery }\end{array}$ \\
\cline { 2 - 2 } & $\begin{array}{l}\text { Diagnosis is made by visualization of pus } \\
\text { from the site, wounds that burst } \\
\text { spontaneously, and a positive result on } \\
\text { microbiological testing }\end{array}$ \\
\hline Organ/ & $\begin{array}{l}\text { Infection of an organ or a body spaces } \\
\text { underlying the fascia/muscle layers that } \\
\text { was handled during surgery }\end{array}$ \\
\cline { 2 - 2 } space SSI & $\begin{array}{l}\text { Patients will have clinical signs of } \\
\text { infection and symptoms pertaining to the } \\
\text { extent of infection/organ damage }\end{array}$ \\
\hline
\end{tabular}

SSI surgical site infection

those who are current smoker; or those having immunosuppression. Other risk factors include emergency procedure, wounds of increasing complexity, prolonged surgeries, contaminated environmental surfaces, lack of strict asepsis in the operating room, inappropriate antibiotic with respect to choice/timing/weight-based dosing, impaired glycemic control, etc. [6].

Maintaining strict asepsis during wound handling and timely administration of the correct antibiotics in appropriate doses are the most important factors to prevent SSI. Other measures such as hand hygiene, skin antisepsis, avoiding shaving of hair (if necessary, to clip), and use of double gloves and other barrier devices are also recommended by various societies for reducing SSI.

\section{Prophylaxis for SSI}

\section{Antimicrobial Prophylaxis}

Surgical antimicrobial prophylaxis (AMP) is the administration of a short-course antibiotic to reduce the microbial burden at the time of skin incision. An ideal AMP program has to select the antibiotics that are active against the likely
Table 9 Strong recommendations from CDC regarding prevention of SSI

Bath with water and soap on the night prior to surgery

Administer AMP ONLY IF indicated, and AMP to be administered in the correct time and correct dose such that optimal bactericidal concentration of the agents is established in the serum and tissues when the incision is made

Administer AMP for all caesarean section procedures

Use an alcohol-based antiseptic agent for surgical site preparation unless otherwise specified

Avoid application of all antimicrobial agents including ointments, solutions, or powders to the surgical incision

Use of antibiotic (triclosan)-coated sutures

Strict glycemic control in the perioperative period with target blood glucose levels less than $200 \mathrm{mg} / \mathrm{dL}$ in all patients irrespective of diabetic status

Maintain perioperative normothermia

Optimize tissue oxygenation by maintaining

normothermia and euvolumia

Provide an increased $\mathrm{FIO}_{2}$ during surgery and in the immediate postoperative period after extubation

Transfuse blood and blood products as per transfusion thresholds

Avoid additional AMP after closure of the surgical incision in the operating room

$C D C$ Centre for Disease Control and Prevention, AMP antimicrobial prophylaxis

pathogens at the surgical site and administer the optimum dose at correct time, so that adequate serum and tissue concentrations are achieved. It is recommended that the full dosa should be administered within $60 \mathrm{~min}$ of the surgical incision and re-dosed as per the half-life of the drug or in case of blood loss more than one third of circulating blood volume.

Cefazolin as a single agent is the recommended drug of choice for cardiothoracic and upper gastrointestinal surgeries, surgery of non-obstructed small bowel, cesarean section, orthopedic surgery, spinal surgery, and neurosurgery. In patients with allergy to cefazolin, aminoglycosides such as gentamycin may be used. Infective endocarditis prophylaxis is restricted to specific procedures in patients with few high-risk cardiac conditions.

\section{Other Methods for Prevention of SSI}

The CDC recommendation for prevention of SSI is outlined in Table 9 [7]. 


\section{Conclusion}

Nosocomial infections increase patient's morbidity, hospital and ICU length of stay, treatment costs, and mortality. They are also responsible for increased antibiotic use, leading to antibiotic resistance and outbreaks of multidrug-resistant infections. Implementing and enforcing infection control measures is the pivotal step toward curbing the nosocomial infection. Increased awareness, health education, and adhering to care bundles have been proved to be efficacious in reducing nosocomial infections.

\section{References}

1. Al-Abdely HM, et al. Impact of the International Nosocomial Infection Control Consortium (INICC)'s multidimensional approach on rates of ventilatorassociated pneumonia in intensive care units in 22 hospitals of 14 cities of the Kingdom of Saudi Arabia. J Infect Public Health. 2018;11:677-84. Elsevier. https://doi.org/10.1016/j.jiph.2018.06.002.

2. Al-Mousa HH, et al. Impact of the International Nosocomial Infection Control Consortium (INICC) multidimensional approach on rates of ventilator-associated pneumonia in intensive care units of two hospitals in Kuwait. J Infect Prev. 2018;19:168-76. https://doi.org/ $10.1177 / 1757177418759745$.

3. Álvarez-Lerma F, et al. Prevention of ventilator-associated pneumonia. Crit Care Med. 2018;46(2):181-8.

4. Álvarez Lerma F, Sánchez García M, Lorente L, et al. Guidelines for the prevention of ventilator-associated pneumonia and their implementation. The Spanish "Zero-VAP" bundle. Med Intensiva. 2014;38:226-36.

5. Azoulay E, et al. The intensive care medicine research agenda on critically ill oncology and hematology patients. Intensive Care Med. 2017;43(9):1366-82.

6. Ban KA, et al. American College of Surgeons and surgical infection society: surgical site infection guidelines, 2016 update. J Am Coll Surg. 2017;224(1):59-74.

7. Berríos-Torres SI, et al. Centers for Disease Control and Prevention guideline for the prevention of surgical site infection, 2017. JAMA Surg. 2017;152(8):784-91.

8. Borchardt RA, Tzizik D. Update on surgical site infections: the new CDC guidelines. J Am Acad Physician Assist. 2018;31(4):52-4.

9. Bouadma L, et al. Use of procalcitonin to reduce patients' exposure to antibiotics in intensive care units (PRORATA trial): a multicentre randomised controlled trial. Lancet. 2010;375(9713):463-74.

10. Canadian Critical Care Trials Group. A randomized trial of diagnostic techniques for ventilator-associated pneumonia. N Engl J Med. 2006;355:2619-30.
11. CDC. CDC/NHSN surveillance definitions for specific types of infections. 2018a;(17), pp 1-30.

12. CDC. Urinary tract infection (Catheter-Associated Urinary Tract Infection [CAUTI] and non-catheter-associated urinary tract infection [UTI]) and other urinary system infection [USI]) events. 2018b. Available at: https://www.cdc.gov/nhsn/PDFs/pscManual/7pscCAUTI current.pdf. Accessed 14 Jul 2018.

13. Centers for Disease Control. Healthcare-associated Infections (HAI) progress report|HAI|CDC, Centers for Disease Control and Prevention. 2016. Available at: https:/www.cdc.gov/hai/surveillance/progress-rep ort/index.html. Accessed 13 Jul 2018.

14. Chakravarthy $\mathrm{M}$, et al. The impact of the international nosocomial infection control consortium (INICC) multicenter, multidimensional hand hygiene approach in two cities of India. J Infect Public Health. 2015; $8(2): 177-86$

15. Chalmers JD, et al. Healthcare-associated pneumonia does not accurately identify potentially resistant pathogens: a systematic review and meta-analysis. Clin Infect Dis. 2014;58(3):330-9.

16. Chenoweth C, Saint S. Preventing catheter-associated urinary tract infections in the intensive care unit. Crit Care Clin. 2013;29(1):19-32.

17. Coffin SE, et al. Strategies to prevent ventilatorassociated pneumonia in acute care hospitals. Infect Control Hosp Epidemiol. 2008;29(Suppl. 1):S31-40.

18. Cook B. Preventing ventilator associated pneumonia (VAP). Health Protection Scotland. 2016. http://www. hps.scot.nhs.uk/haiic/ic/resourcedetail.aspx?id=987. Accessed 12 Jul 2018.

19. Cornejo-Juárez $P$, et al. The impact of hospitalacquired infections with multidrug-resistant bacteria in an oncology intensive care unit. Int J Infect Dis. 2015;31:31-4.. https://www.sciencedirect.com/scienc e/article/pii/S1201971214017408

20. Cornejo-Juárez P, et al. Hospital-acquired infections at an oncological intensive care cancer unit: differences between solid and hematological cancer patients. BMC Infect Dis. BioMed Central. 2016;16:274.

21. Dias Margarida MP, Amaro P. Ventilator-associated pneumonia (VAP) - early and late-onset differences. Eur Respir J. 2013;42(Suppl 57):P2457.

22. Ekren PK, et al. Evaluation of the 2016 Infectious Diseases Society of America/American Thoracic Society guideline criteria for risk of multidrug-resistant pathogens in patients with hospital-acquired and ventilator-associated pneumonia in the ICU. Am J Respir Crit Care Med. 2018;197(6):826-30.

23. El-Saed A, Balkhy HH, Weber DJ. Benchmarking local healthcare-associated infections: available benchmarks and interpretation challenges. J Infect Public Health. 2013;6(5):323-30.

24. Garner JS, et al. CDC definitions for nosocomial infections, 1988. Am J Infect Control. 1988;16(3):128-40.

25. Giuliano KK, Baker D, Quinn B. The epidemiology of nonventilator hospital-acquired pneumonia in the United States. Am J Infect Control. 2018;46(3):322-7. 
26. Golia S, K T S, C L V. Microbial profile of early and late onset ventilator associated pneumonia in the intensive care unit of a tertiary care hospital in Bangalore, India. J Clin Diagn Res. JCDR Research \& Publications Private Limited. 2013;7(11):2462-6. https://doi. org/10.7860/JCDR/2013/6344.3580.

27. Guidelines for the Management of Adults with Hospital-acquired, Ventilator-associated, and Healthcare-associated Pneumonia. Am J Respir Crit Care Med. American Thoracic Society. 2005;171(4): 388-416.

28. Gujar M. Colistin for lung infection: an update. J Intensive Care. 2015;22(3):3.

29. Herer B, et al. Management of nosocomial pneumonia on a medical ward: a comparative study of outcomes and costs of invasive procedures. Clin Microbiol Infect. 2009; 15(2):165-72.

30. Hooton TM, et al. Diagnosis, prevention, and treatment of catheter-associated urinary tract infection in adults: 2009 international clinical practice guidelines from the Infectious Diseases Society of America. Cl Infect Dis: Off Publ Infect Dis Soc Am. 2010;50(5):625-63.

31. Hunter. Ventilator associated pneumonia. BMJ. 2012;344:e3325.

32. Ibn Saied W, Souweine B, Garrouste-Orgeas M, Ruckly S, Darmon M, Bailly S, et al. Respective impact of implementation of prevention strategies, colonization with multiresistant bacteria and antimicrobial use on the risk of early- and late-onset VAP: an analysis of the OUTCOMEREA network. PLoS One. 2017;12(11):e0187791. https://doi.org/10.1371/journal.pone. 0187791

33. IHI. Institute for healthcare improvement: how-to guide: prevent ventilator-associated pneumonia. 2012. Available at: http://www.ihi.org/resources/Pages/Tool s/HowtoGuidePreventVAP.aspx. Accessed 12 Jul 2018.

34. Institute for Healthcare Improvement: Evidence-Based Care Bundles n.d.. Available at: http://www.ihi.org/ Topics/Bundles/Pages/default.aspx. Accessed 17 Jul 2018.

35. Institute For Healthcare Improvement, I. Institute for healthcare improvement: how-to guide: prevent ventilator-Associated pneumonia. 2012. Available at: http://www.ihi.org/resources/Pages/Tools/HowtoG uidePreventCatheterAssociatedUrinaryTractInfection. aspx. Accessed 17 Jul 2018.

36. Jamal J-A, Abdul-Ain M-H, Lipman J, Roberts JA. Defining antibiotic dosing in lung infections. Clin Pulm Med. 2013;20(3):121-8.

37. Jones BE, et al. Trends in antibiotic use and nosocomial pathogens in hospitalized veterans with pneumonia at 128 medical centers, 2006-2010. Clin Infect Dis. 2015;61(9):1403-10.

38. Swanson JM, Wells DL. Empirical antibiotic therapy for ventilator-associated pneumonia. Antibiotics (Basel). 2013;2(3):339-51.

39. Kalanuria AA, et al. Ventilator-associated pneumonia in the ICU. Crit care. BioMed Central. 2014;18(2):208.
40. Kalil AC, et al. Management of Adults with hospitalacquired and ventilator-associated pneumonia: 2016 clinical practice guidelines by the Infectious Diseases Society of America and the American Thoracic Society. Clin Infect Dis. 2016;63(5):e61-e111.

41. Khan HA, Ahmad A, Mehboob R. Nosocomial infections and their control strategies. Asian Pac J Trop Biomed. 2015;509-514 https://doi.org/10.1016/j.apjtb 2015.05.001.

42. Khan HA, Baig FK, Mehboob R. Nosocomial infections: epidemiology, prevention, control and surveillance. Asian Pac J Trop Biomed. Elsevier B.V. 2017;7(5):478-82. https://doi.org/10.1016/j.apj tb.2017.01.019.

43. Khan P, Divatia JV. Severe sepsis bundles. Indian J Crit Care Med. 2010;14(1):8-13.

44. Klavs I, et al. Prevalence of and risk factors for hospital-acquired infections in Slovenia-results of the first national survey, 2001. J Hosp Infect. 2003; 54(2):149-57.

45. Klavs I, et al. The prevalence of and risk factors for healthcare-associated infections in Slovenia: results of the second national survey. Zdravstveno varstvo. 2016;55(4):239-47.

46. Klevens RM, et al. Estimating health care-associated infections and deaths in U.S. hospitals, 2002. Public Health Rep (Washington, DC: 1974). 2007;122(2): 160-6.

47. Klompas M, et al. Reappraisal of routine oral care with chlorhexidine gluconate for patients receiving mechanical ventilation. JAMA Intern Med. 2014;174(5):751.

48. Köves B, et al. Benefits and harms of treatment of asymptomatic bacteriuria: A systematic review and meta-analysis by the European Association of Urology urological infection guidelines panel. Eur Urol. 2017;72(6):865-8.

49. Kuti EL, Patel AA, Coleman C. Impact of inappropriate antibiotic therapy on mortality in patients with ventilatorassociated pneumonia and blood stream infection: a meta-analysis. J Crit Care. 2008;23(1):91-100.

50. Langer M, Cigada M, Mandelli M, Mosconi P, G T. Early onset pneumonia: a multicenter study in intensive care units. Intensive Care Med. 1987;13:342-6.

51. Iannella HA, Luna CM. Treatment failure in ventilator associated pneumonia. Curr Respir Med Rev. 2012;8:239-44.

52. Mao Z, et al. Subglottic secretion suction for preventing ventilator-associated pneumonia: an updated meta-analysis and trial sequential analysis. Crit Care (London). 2016;20(1):353. https://doi.org/10.1186/ s13054-016-1527-7.

53. Kollef MH, Afessa B, Antonio Anzueto M, et al. Silver-coated endotracheal tubes and incidence of ventilator-associated pneumonia the NASCENT randomized trial. JAMA. 2008;300(7):805-13.

54. Martin-Loeches I, Rodriguez AH, Torres A. New guidelines for hospital-acquired pneumonia/ventilator-associated pneumonia: USA vs. Europe. Curr Opin Crit Care. 2018;24(5):347-52. 
55. Mehta Y, et al. Guidelines for prevention of hospital acquired infections. Indian J Crit Care Med. 2014;18(3):149-63.

56. Mehta Y, et al. Effectiveness of a multidimensional approach for prevention of ventilator-associated pneumonia in 21 adult intensive-care units from 10 cities in India: findings of the International Nosocomial Infection Control Consortium (INICC). Epidemiol Infect. 2013;141(12):2483-91. https://doi.org/10.101 7/S0950268813000381.

57. Melsen WG, et al. Attributable mortality of ventilatorassociated pneumonia: a meta-analysis of individual patient data from randomised prevention studies. Lancet Infect Dis. 2013;13(8):665-71.

58. Muscedere J, et al. Comprehensive evidence-based clinical practice guidelines for ventilator-associated pneumonia: prevention. J Crit Care. 2008;23(1):126-37.

59. Niederman MS. Antibiotic treatment of hospitalacquired pneumonia. Curr Opin Crit Care. 2018;24(5):353-60.

60. Papazian L, Thomas P, Garbe L, et al. Bronchoscopic or blind sampling techniques for the diagnosis of ventilator-associated pneumonia. Am J Respir Crit Care Med. 1995;152:1982-91.

61. Pappas PG, et al. Clinical practice guideline for the management of candidiasis: 2016 update by the Infectious Diseases Society of America. Clin Infect Dis. 2016;62(4):e1-50.

62. Di Pasquale M, et al. Non-intensive care unit acquired pneumonia: a new clinical entity? Int J Mol Sci. 2016;17(3):287.

63. Pickard R, et al. Antimicrobial catheters for reduction of symptomatic urinary tract infection in adults requiring short-term catheterisation in hospital: a multicentre randomised controlled trial. Lancet (London). 2012;380(9857):1927-35.

64. Ramirez J, et al. Randomized phase 2 trial to evaluate the clinical efficacy of two high-dosage tigecycline regimens versus imipenem-cilastatin for treatment of hospital-acquired pneumonia. Antimicrob Agents Chemother. 2013;57(4):1756-62.

65. Ranzani OT, De Pascale G, Park M. Diagnosis of nonventilated hospital-acquired pneumonia. Curr Opin Crit Care. 2018;24(5):339-46.

66. Richards MJ, Edwards JR, Culver DH, Gaynes RP. Nosocomial infections in medical intensive care units in the United States. Crit Care Med. 1999; 27:887-92.

67. Rosenthal VD, et al. Surgical site infections, international nosocomial infection control consortium (INICC) report, data summary of 30 countries, 2005-2010. Infect Control Hosp Epidemiol. 2013; 34(06):597-604.

68. Rosenthal VD, et al. International nosocomial infection control consortium report, data summary of 50 countries for 2010-2015: device-associated module. Am J Infect Control. 2016;44(12):1495-504.

69. Rosenthal VD, et al. Impact of the international nosocomial infection control consortium's multidimensional approach on rates of ventilator-associated pneumonia in 14 intensive care units in 11 hospitals of 5 cities within Argentina. Am J Infect Control. 2018;46(6):674-9.

70. Saint S, et al. A program to prevent catheter-associated urinary tract infection in acute care. N Engl J Med. Massachusetts Medical Society. 2016;374(22):2111-9.

71. Shah PS, et al. Controlling antimicrobial use and decreasing microbiological laboratory tests for urinary tract infections in spinal-cord-injury patients with chronic indwelling catheters. Am J Health Syst Pharm. 2005;62(1):74.

72. Shalini $S$, et al. Impact and effect of nosocomial infections: a review. Res J Pharm, Biol Chem Sci. 2015;6(1):947-51.

73. Silverman JA, et al. Inhibition of daptomycin by pulmonary surfactant: in vitro modeling and clinical impact. J Infect Dis. 2005;191(12):2149-52.

74. Singer M. Biomarkers in sepsis. Curr Opin Pulm Med. 2013;19(3):305-9.

75. Sole Violan J, Fernandez JA, Benitez AB, et al. Impact of quantitative invasive diagnostic techniques in the management and outcome of mechanically ventilated patients with suspected pneumonia. Crit Care Med. 2000;28:2737-41.

76. Surbatovic M, et al. Immunoinflammatory response in critically ill patients: severe sepsis and/or trauma. Mediat Inflamm. Hindawi Limited. 2013; 2013:362793. https://doi.org/10.1155/2013/362793.

77. Tariq A, Ali H, Zafar F, Sial AA, Hameed K, et al. A systemic review on surgical site infections: classification, risk factors, treatment complexities, economical and clinical scenarios. J Bioequivalence Bioavailab. 2017;9:336-40. https://doi.org/10.4172/jbb.1000321.

78. Torres A, et al. International ERS/ESICM/ESCMID/ ALAT guidelines for the management of hospitalacquired pneumonia and ventilator-associated pneumonia: guidelines for the management of hospitalacquired pneumonia (HAP)/ventilator-associated pneumonia (VAP) of the European Respiratory Society (ERS), European Society of Intensive Care Medicine (ESICM), European Society of Clinical Microbiology and Infectious Diseases (ESCMID) and Asociación Latinoamericana del Tórax (ALAT). Eur Respir J. 2017;50(3):1700582.

79. Torres A, et al. Summary of the international clinical guidelines for the management of hospital-acquired and ventilator-acquired pneumonia. ERJ Open Res. 2018;4(2):00028-2018. https://doi.org/10.1183/23120 541.00028-2018.

80. Umscheid CA, Mitchell MD, Doshi JA, et al. Estimating the proportion of healthcare-associated infections that are reasonably preventable and the related mortality and costs. Infect Control Hosp Epidemiol. 2011;32(2):101-14.

81. Valcke Y, Pauwels R, Van der Straeten M. Pharmacokinetics of antibiotics in the lungs. Eur Respir J. 1990;3(6):715-22.

82. Vincent J, Rello J, Marshall J, Silva E, Anzueto A, Martin C, Moreno R, Lipman J, Gomersall C, Sakr Y, R. K. International study of the prevalence and 
outcomes of infection in intensive care units. JAMA. 2009;302(21):2323-9.

83. Vincent J-L, et al. The prevalence of nosocomial infection in intensive care units in Europe. JAMA. 1995;274(8):639-44.

84. Wacker C, et al. Procalcitonin as a diagnostic marker for sepsis: a systematic review and meta-analysis. Lancet Infect Dis. 2013;13(5):426-35.

85. Wang Y, et al. National Trends in patient safety for four common conditions, 2005-2011. N Engl J Med. 2014;370(4):341-51.

86. Weber DJ, Raasch R, Rutala WA. Nosocomial infections in the ICU: the growing importance of antibioticresistant pathogens. Chest. 1999;115(3):34S-41S.
87. Weigelt JA, Lipsky BA, Tabak YP, et al. Surgical site infections: control., causative pathogens and associated outcomes. Am J Infect. n.d.;38(2):112-20.

88. WHO|My 5 Moments for Hand Hygiene. WHO. World health organization. 2017. Available at: http://www. who.int/infection-prevention/campaigns/clean-hands/ 5moments/en/. Accessed 17 Jul 2018.

89. Zilberberg MD, Shorr AF. Ventilator-associated pneumonia: the clinical pulmonary infection score as a surrogate for diagnostics and outcome. Clin Infect Dis. 2010;51(S(1)):S131-5. 